\title{
USO DO COEFICIENTE DE REPETIBILIDADE NA SELEÇÃO DE CLONES DE PESSEGUEIRO PARA O LITORAL SUL DE SANTA CATARINA ${ }^{1}$
}

\author{
EMILIO DELLA BRUNA², ALEXSANDER LUÍS MORETO³, MARCO ANTONIO DALBÓ ${ }^{4}$
}

RESUMO - O presente trabalho teve como objetivo estimar os coeficientes de repetibilidade de caracteres relacionados à produtividade do pessegueiro, além de identificar e selecionar clones promissores para o Litoral Sul de Santa Catarina. Foram selecionadas plantas híbridas que apresentavam boa adaptação ao clima, produção, tamanho, sabor e firmeza dos frutos. Essas seleções foram enxertadas sobre o porta -enxerto Okinawa e plantadas no ano de 2005, em três diferentes locais: 1- Estação Experimental de Urussanga, situada a 40 metros de altitude; 2- Propriedade de fruticultor, situada a 200 metros de altitude; 3 - Propriedade de fruticultor, situada a 350 metros de altitude. As mudas foram plantadas no espaçamento de $6 \times 1$ metros e conduzidas no sistema de V . As avaliações foram realizadas durante os anos de 2007 e 2008. Os coeficientes de repetibilidade foram estimados pelo método da máxima verossimilhança restrita (REML), e a predição dos valores fenotípicos e genotípicos, pela melhor predição linear não viciada (BLUP), por meio do software Selegen-REML/BLUP. Todos os caracteres apresentaram considerável variabilidade genética, com estimativas de coeficientes de repetibilidade (r) variando de média a alta magnitude $(0,54$ a 0,74$)$ para o caráter massa média dos frutos (MMF) e de baixa a média magnitude $(0,22$ a 0,39$)$ para o caráter produção de frutos/planta (PTF). Os clones 1770 e 1443 apresentaram bom desempenho na média de todos os locais, enquanto os clones 0470 e 1307 se destacaram no local 1, o clone 1444 no local 2, os clones 0740 e 0926 no local 3 e o clone 1770 nos locais 1 e 2 de avaliação.

Termos para indexação: pessegueiro, melhoramento genético, coeficiente de repetibilidade, Reml/Blup.

\section{REPEATABILITY IN THE SELECTION OF CLONES OF PEACH FOR THE SOUTH COASTAL REGION OF THE STATE OF SANTA CATARINA, BRAZIL}

\begin{abstract}
The aim of the present study was estimate the coefficients of repeatability for productive features in peach, in addition to identify and select promising clones for the south coastal region of the State of Santa Catarina, Brazil. Hybrid plants that showed good adaptation to the climate, production, size, flavor and firmness of fruit were selected. These selections were then grafted on Okinawa rootstock and planted in the year 2005 in three different locations: 1 - Experimental Station of Urussanga, at 40 meters of altitude; 2 - Grower's orchard, at 200 meters of altitude; 3 - Grower's orchard, at 350 meters of altitude. The seedling were planted in a spacing of $6 \times 1$ meters and conducted in V system. Evaluations were carried out during the years 2007 and 2008. Variance components were estimated by Restricted Maximum Likelihood (REML), and the prediction of phenotypic and genotypic values by Best Linear Unbiased Prediction (BLUP), using the software Selegen-REML/BLUP. All productive features showed considerable genetic variability, with the estimations of repeatability coefficient (r) ranging from medium to high magnitude (0.54 to 0.74 ) for mean fruit weight (MMF), and from low to medium magnitude $(0.22$ to 0.39$)$ for the number of fruits per plant (PTF). Clones 1770 and 1443 showed a good performance on average across all sites, while clones 0470 and 1307 performed better in site 1, clone 1444 in site 2, clones 0740 and 0926 in site 3, clone 1770 in sites 1 and 2.
\end{abstract}

Index terms: peach, plant breeding, coefficients of repeatability, Reml/Blup.

\footnotetext{
'(Trabalho 079-11). Recebido em: 08-02-2011. Aceito para publicação em: 01-11-2011

${ }^{2}$ Eng.agr., M.Sc., Epagri/Estação Experimental de Urussanga, Rodovia SC-446, km 16, C.P. 49, 88840-000 Urussanga-SC, e-mail: emilio@epagri.sc.gov.br

${ }^{3}$ Eng. Agr., Dr., Epagri/Estação Experimental de Urussanga, , Rodovia SC-446, km 16, C.P. 49, 88840-000 Urussanga-SC, e-mail: alexsandermoreto@epagri.sc.gov.br

${ }^{4}$ Eng. Agr., Ph.D., Epagri/Estação Experimental de Videira, C.P. 21, 89560-000, Videira-SC, e-mail: dalbo@epagri@sc.gov.br

Suporte finaceiro: FAPESC
} 


\section{INTRODUÇÃO}

O pessegueiro Prunus persica L. Batsch, originário da China, é considerado frutífera típica de clima temperado, sendo uma das espécies que mais têm sido pesquisadas quanto a adaptações a condições de clima temperado quente ou subtropical. No Brasil, a cultura do pessegueiro tem-se desenvolvido bastante e ocupado um espaço crescente no mercado nos últimos anos. Segundo dados da Central de Abastecimento do Estado de São Paulo (CEAGESP, 2005), o movimento das frutas de caroço, notadamente pêssegos e ameixas, cresceram na ordem de 600\% só no período de 1992 a 1997. No Litoral Sul, no Médio Vale do Itajaí e no extremo Oeste Catarinense existem condições climáticas favoráveis para produção de pêssegos desde que se utilizem cultivares com baixa exigência em frio hibernal e com boa qualidade de frutos.

O pessegueiro é uma espécie que apresenta grande variabilidade em características, como hábito de crescimento, formato das folhas e gemas, resistência a doenças e exigência em frio hibernal, assim como em produtividade e massa média de frutos. Hoje, graças aos programas de melhoramento existentes no mundo, há cultivares que necessitam de pouco mais de 50 horas de frio, havendo outras que necessitam de mais de mil horas de frio (BARBOSA et al., 1997).

Devido ao longo prazo e aos altos custos na condução dos programas de melhoramento de culturas perenes, como o pessegueiro, torna-se de grande importância o uso de procedimentos de seleção mais acurados. Os caracteres de interesse no melhoramento do pessegueiro expressam-se mais de uma vez em cada indivíduo, gerando dados de colheitas ou medidas repetidas. A análise desses experimentos de colheitas (ou medidas) repetidas nas mesmas parcelas e/ou indivíduos apresenta peculiaridades pelo fato de várias colheitas serem correlacionadas entre si e pela possibilidade de haver heterogeneidade de variâncias e de covariâncias entre várias safras colhidas (RESENDE, 2007).

A seleção baseada em procedimento biométrico inadequado pode ser ineficiente devido ao confundimento entre efeitos genotípicos e efeitos ambientais. Nesta situação, o procedimento ótimo de seleção é o que envolve a estimação de componentes de variância pelo método da máxima verossimilhança restrita (REML) e a predição dos valores genotípicos pela melhor predição linear não viciada (BLUP) (RESENDE, 2002). Esses componentes de variância permitem a estimação de parâmetros genéticos, dentre os quais os mais importantes são a herdabilidade e a repetibilidade.

O conhecimento do coeficiente de repetibilidade das características de interesse permite avaliar o dispêndio de tempo e de mão de obra necessários para que a seleção de indivíduos geneticamente superiores seja feita com a acurácia desejada pelo pesquisador. Considerando o padrão de duas medições, Resende (2002) propõe a seguinte classificação para o coeficiente de repetibilidade: repetibilidade alta $(\mathrm{r} \geq 0,60)$; repetibilidade média $(0,30<\mathrm{r}<0,60)$, e repetibilidade baixa $(\mathrm{r} \leq 0,30)$. Valores altos da estimativa do coeficiente de repetibilidade do caráter avaliado indicam que é possível predizer o valor real dos indivíduos com um número relativamente pequeno de medições (CORNACCHIA et al., 1995), indicando que haverá pouco ganho em acurácia com o aumento do número de medidas (FALCONER, 1987). No entanto, quando a repetibilidade é baixa, grande número de repetições será necessário para que se alcance um valor de determinação satisfatório. O conhecimento do coeficiente de repetibilidade permite, portanto, que a fase de avaliação seja executada com eficiência, mas com dispêndio mínimo de tempo e mão de obra.

As principais vantagens práticas do REML/ BLUP são: permite comparar indivíduos ou variedades através do tempo (gerações, anos) e espaço (locais, blocos); simultânea correção para os efeitos ambientais, estimação de componentes de variância e predição de valores genéticos; lida com estruturas complexas de dados (medidas repetidas, diferentes anos, locais e delineamentos); pode ser aplicado a dados desbalanceados e a delineamentos não ortogonais (RESENDE, 2002).

O presente trabalho teve como objetivo estimar os coeficientes de repetibilidade de caracteres relacionados à produtividade do pessegueiro, além de identificar e selecionar clones promissores para o Litoral Sul de Santa Catarina.

\section{MATERIAL E MÉTODOS}

Plantas híbridas originadas de cruzamentos entre variedades de pessegueiro com uma ou mais características superiores para: 1-tamanho de fruto; 2-coloração da película; 3-firmeza dos frutos; 4-baixa exigência em frio; e 5-regularidade na produção, foram plantadas e avaliadas em propriedades de fruticultores na região de Urussanga-SC. Dos campos de plantio com plantas híbridas, após o segundo ano de produção, foram selecionadas as que apresentavam boa adaptação ao clima e produção de frutos com tamanho, sabor, firmeza e visual adequados para a época de maturação. Essas seleções foram enxertadas sobre o porta-enxerto Okinawa e 
plantadas no ano de 2005, em três diferentes locais: 1- Estação Experimental de Urussanga, situada a 40 $\mathrm{m}$ de altitude; 2 - Propriedade de fruticultor, situada a $200 \mathrm{~m}$ de altitude; 3 - Propriedade de fruticultor, situada a $350 \mathrm{~m}$ de altitude. Em cada local, uma muda de cada seleção foi plantada no espaçamento de $6 \mathrm{x}$ $1 \mathrm{~m}$ e conduzida no sistema de V. Dessa forma, as parcelas experimentais corresponderam a uma planta, nas quais foram realizadas duas medições (colheita), em duas safras consecutivas. O número de clones testados em cada local foi o seguinte: local 1 - 228 clones; local 2 - 94 clones, e no local 3 - 172 clones. Dos clones testados nos três locais, 84 deles foram comuns aos três locais.

A manutenção dos campos de seleção foi feita pelos fruticultores proprietários das áreas, e o manejo das plantas e a coleta de dados foram realizados pela equipe de pesquisa da Epagri. $\mathrm{O}$ raleio foi feito antes do endurecimento do caroço, entre 30 e 40 dias após a floração, retirando-se o excesso de frutos manualmente. A quantidade de frutos por planta foi definida em função do diâmetro do tronco a 20 centímetros do solo, conforme tabela descrita por Medeiros e Raseira (1998). Foram feitas duas podas verdes por ciclo, nos meses de novembro e janeiro, retirando-se os ramos com excesso de crescimento. No mês de junho, realizou-se a poda de inverno com a retirada do excesso de ramos. Para todos os locais, foram avaliadas as seguintes variáveis: produção (gramas) de frutos por planta (PTF) e massa média dos frutos (MMF); coloração dos frutos (polpa e película); acidez e firmeza dos frutos. As avaliações foram realizadas durante os anos de 2007 e 2008. Após a coleta dos dados, procedeu-se à análise de variância, por local, conforme esquema da Tabela 1 proposto por Resende (2002).

Os componentes de variância foram estimados pelo método da máxima verossimilhança restrita (REML), e a predição dos valores fenotípicos e genotípicos, pela melhor predição linear não viciada (BLUP), por meio do software Selegen-REML/BLUP (RESENDE, 2002).

Foram utilizados os seguintes modelos estatísticos:

modelo 63 (modelo básico de repetibilidade sem delineamento) apresentado por Resende (2007) nas análises por local: esse modelo pode ser usado quando são tomados dados repetidos em plantas individuais sem o uso de delineamentos experimentais. Pode também ser usado quando se trabalha com médias de genótipos avaliados. O modelo estatístico é expresso por: $y=X m+W p+e$, em que: $y$ é o vetor de dados; $m$ é o vetor dos efeitos de medição (assumidos como fixos) somados à média geral; $p$ é o vetor dos efeitos permanentes de plantas (efeitos genotípicos + efeitos de ambiente permanente) (assumidos como aleatórios), e e é o vetor de erros ou resíduos (aleatórios). As letras maiúsculas representam as matrizes de incidência para os efeitos de $\mathrm{m}$ e $\mathrm{p}$, respectivamente.

Foi realizada, separadamente, análise dos 84 clones comuns aos três locais, considerando cada local como um bloco (repetição), portanto três repetições. Assim, os dados foram analisados estatisticamente, seguindo o delineamento em blocos completos, com três repetições e duas medições/ colheitas conforme o modelo 29 (delineamento em blocos completos) apresentado por Resende (2007), para a determinação dos componentes da variância (REML individual). O modelo estatístico é expresso por: $y=X m+Z g+W p+e$, em que: $y$ é o vetor de dados; $m$ é o vetor dos efeitos das combinações medição-repetição (assumidos como fixo) somados à média geral; $g$ é o vetor dos efeitos genotípicos (assumidos como aleatórios); $p$ é o vetor dos efeitos de ambiente permanente (parcelas no caso) (aleatórios), e $e$ é o vetor de erros ou resíduos (aleatórios). As letras maiúsculas representam as matrizes de incidência para os efeitos de $\mathrm{m}$, g e $\mathrm{p}$, respectivamente. $\mathrm{O}$ vetor $\mathrm{m}$ contempla as medições em todos os blocos (repetições) e ajustam, simultaneamente, para efeitos de blocos, medição e interação blocos x medições. O intuito principal desse tipo de análise é a seleção de clones que, na média dos três ambientes, tenha bom desempenho e apresentem características desejáveis para futura recomendação comercial em uma região de maior abrangência edafoclimática.

\section{RESULTADOS E DISCUSSÃO}

Na Tabela 2, são apresentadas as análises de variância, por local, bem como as estimativas dos componentes da variância para os caracteres produção total de frutos/planta (PTF) e massa média dos frutos (MMF). Detectaram-se diferenças significativas $(P \leq 0,01 ; P \leq 0,05)$ pelo teste $\mathrm{F}$, para as variáveis avaliadas, para os fatores colheita/medição e clones, nos três ambientes estudados. Estes resultados refletem a existência de variabilidade entre os clones avaliados com possibilidades de sucesso com a seleção de indivíduos superiores.

A diferente resposta dos genótipos nos diferentes anos agrícolas (medição/colheita) avaliados evidencia aumento significativo da produtividade dos clones de uma safra para outra, por se tratar de pomares novos e ainda em fase de desenvolvimento. Os maiores coeficientes de variação foram estimados para PTF variando de $35,05 \%$ a $58,31 \%$ (Tabela 2).

As estimativas dos componentes da variân- 
cia referentes ao PTF e MMF nos vários ambientes foram obtidos pelo modelo 63 (modelo básico), conforme Resende (2007) (Tabela 2). É relevante a predição dos valores genéticos, genotípicos e fenotípicos permanentes, para atender aos dois principais propósitos do presente trabalho, que são: a) selecionar indivíduos que serão mantidos em seu próprio microambiente em que estão sendo avaliados, e dessa forma capitalizam-se os efeitos aditivos, de dominância e ambiente permanente; b) selecionar indivíduos para propagá-los vegetativamente, ou seja, fora do microambiente em que estão sendo testados, e dessa forma capitalizam-se os efeitos aditivos e de dominância.

Observa-se que, para o caráter MMF, a variância fenotípica permanente (Vfp) representa a maior porcentagem da variância fenotípica (Vf) em todos os ambientes de avaliação, indicando a possibilidade de sucesso ao se selecionar genótipos para cada microrregião onde foram avaliados, sendo o sucesso capitalizado se as novas mudas forem provenientes de propagação assexuada, como foi o caso. Nota-se que o coeficiente de repetibilidade individual (r) variou entre 0,54 e 0,74 para o caráter MMF, sendo consideradas de média e alta magnitudes, respectivamente, segundo Sturion e Resende (2005), com estimativas de acurácia (Acm) superiores a $83,8 \%$, o que demonstra a regularidade da superioridade dos indivíduos de uma safra para outra, e que a expressão dessa característica tem bom controle genético (Tabela 2). Esses valores indicam que a variância ambiental, para essa característica, foi relativamente baixa, comparada com a variância existente entre plantas. Resultados semelhantes foram obtidos em laranjeiras-doces (NEGREIROS et al., 2008), aceroleira (LOPES et al., 2001), mangueira (COSTA, 2003) e umbuzeiro (SANTOS, 1999). Para o caráter PTF, a repetibilidade (r) variou entre 0,22 e 0,39 com estimativas de acurácia (Acm) entre 60,0 e 75,0\% (Tabela 2). A acurácia seletiva depende da herdabilidade e da repetibilidade do caráter, da quantidade e da qualidade de informações e dos procedimentos utilizados na predição dos valores genéticos. Como é uma medida que está associada à precisão na seleção, ou seja, refere-se à correlação entre valores genéticos preditos e valores genéticos verdadeiros dos indivíduos, e quanto maior a acurácia na avaliação de um individuo, maior é a confiança na avaliação e no valor genético predito do indivíduo. A acurácia também é o principal elemento do progresso genético, em que o melhorista pode alterar, visando a maximizar o ganho genético (STURION; RESENDE, 2005).

De maneira geral, a utilização dos dados de duas safras consecutivas possibilitou um aumento na eficiência de seleção para ambos os caracteres avaliados. Variou entre 7 e 14\% para MMF e entre 20 e $28 \%$ para PTF (Tabela 2 ).

Nas Tabelas 3, 4 e 5, são apresentados os ordenamentos dos 30 melhores clones classificados, para ambos os caracteres avaliados, em termos de efeito fenotípico permanente em cada local de avaliação. Levando em consideração que para espécies frutíferas existe um padrão para o tamanho dos frutos que são preferidos pelos consumidores, conclui-se que, para cada local, é possível realizar a seleção de clones mais produtivos e que atendam às demandas dos consumidores. No local 1, destacaram-se os clones 0470 e 1307 com produções de 11,2 kg/planta e $10,3 \mathrm{~kg} / \mathrm{planta}$, e frutos pesando em torno de $86 \mathrm{~g}$ e $102 \mathrm{~g}$, respectivamente. No local 2, destacaram-se os clones 1444 e 1770 com produções em tordo dos $8,3 \mathrm{~kg} /$ planta e $7,5 \mathrm{~kg} /$ planta com frutos pesando em torno de $100 \mathrm{~g}$ e $85 \mathrm{~g}$, respectivamente. Já no local 3, os clones 0740 e 0926 destacaram-se com produções de $14,0 \mathrm{~kg} /$ planta e $13,4 \mathrm{~kg} /$ planta, e frutos pesando na ordem de $116 \mathrm{~g}$ e 93,5 g, respectivamente. Os clones 1770 e 0470 apresentaram firmeza média, coloração de película $20 \%$ avermelhada e polpa branca. Os clones 0740; 1307 e 0926 apresentaram as mesmas características de cor de película e polpa que os anteriores, mas com elevada firmeza. Já o clone 1444 possui polpa amarela, película $30 \%$ avermelhada e alta firmeza.

Na Tabela 6, são apresentadas as estimativas dos componentes da variância referentes aos 84 clones de pessegueiro comuns aos três locais de avaliação, considerando cada local como sendo um bloco (repetição), conforme o modelo 29 apresentado por Resende (2007) para ambos os caracteres estudados. Observa-se que o caráter PTF apresentou considerável variância ambiental em relação à genotípica, evidenciando que o caractere foi bastante influenciado pelas condições ambientais dos diferentes locais, fato comprovado pela baixa herdabilidade estimada para tal $(\mathrm{h} 2 \mathrm{~g}=20,9 \%)$. A repetibilidade a nível de parcela ficou em torno de 33,1\%, considerada de média magnitude, conforme classificação de Resende (2002). Para o caráter MMF, observaram-se magnitudes médias de herdabilidade e repetibilidade, evidenciando a existência de uma considerável variação genotípica do caráter e maior possibilidade de sucesso com a seleção destinada a esse propósito. A acurária seletiva estimada foi de $68,9 \%$ e $90,9 \%$ para os caracteres PTF e MMF, respectivamente.

Na Tabela 7, é apresentado o ordenamento dos 30 melhores clones classificados entre os 84 comuns aos três locais, para ambos os caracteres avaliados 
em termos de efeito genotípico predito e média genotípica. Dentre eles, destacaram-se os clones 1770 e 1443 com PTF em torno de $10 \mathrm{~kg} /$ planta e MMF por volta de $81 \mathrm{~g}$. O clone 1443 apresenta firmeza alta, polpa amarela e película $40 \%$ avermelhada. Em relação ao clone 1770 , tais características já foram descritas anteriormente.

Com relação à acidez, os clones 0470; 0926; 0740; 1444 e 1770 são classificados como de baixa e os clones 1307 e 1443 de média acidez, estando assim ao gosto da maioria dos consumidores da fruta.

TABELA 1 - Esquema da análise de variância para cada local de avaliação.

\begin{tabular}{lccc}
\hline \multicolumn{1}{c}{$\mathrm{FV}$} & $\mathrm{GL}$ & $\mathrm{QM}$ & $\mathrm{E}(\mathrm{QM})$ \\
\hline Medição/Colheita & $\mathrm{s}-1$ & $\mathrm{Q} 1$ & $\sigma_{c t}^{2}+s \sigma_{p}^{2}$ \\
Clones & $\mathrm{p}-1$ & $\mathrm{Q} 2$ & $\sigma_{e t}^{2}$ \\
Resíduo & $(\mathrm{p}-1)(\mathrm{s}-1)$ & $\mathrm{Q} 3$ & \\
\hline Total & $\mathrm{sp}-1$ & & \\
\hline
\end{tabular}

em que: $\sigma_{e t}^{2}$ : variância ambiental temporária; $\quad \sigma_{p}^{2}$ : variância genética acrescida da variância de ambiente permanente; p: clones; s: medições/colheitas.

TABELA 2 - Análises de variância, coeficientes de repetibilidade e estimativas dos parâmetros fenotípicos para os caracteres produção (gramas) de frutos/planta (PTF) e massa média dos frutos (MMF), por local.

\begin{tabular}{|c|c|c|c|c|}
\hline \multirow[b]{2}{*}{ Locais } & \multirow[b]{2}{*}{ FV } & \multirow[b]{2}{*}{ GL } & \multicolumn{2}{|c|}{ QM } \\
\hline & & & PTF & MMF \\
\hline \multirow{12}{*}{ Local (1) } & medição/colheita & 1 & $4093884241 * *$ & $597,7358 *$ \\
\hline & Clones & 227 & $20363540 * *$ & $397,0881 * *$ \\
\hline & resíduo & 227 & 8901674 & 95,1062 \\
\hline & C.V. $(\%)$ & & 45,35 & 15,95 \\
\hline & Vfp: & & 5753277,1941 & 151,3688 \\
\hline & Vet: & & 8914267,9875 & 95,2542 \\
\hline & Vf: & & 14667545,1817 & 246,6231 \\
\hline & $\mathrm{r}=\mathrm{h} 2:$ & & $0,39+/-0,083^{1}$ & $0,61+/-0,103^{1}$ \\
\hline & $\mathrm{rm}:$ & & 0,5634 & 0,7606 \\
\hline & Acm: & & 0,7506 & 0,8721 \\
\hline & Eficiência & & 1,20 & 1,11 \\
\hline & Média geral & & 6576,3104 & 61,1268 \\
\hline \multirow{12}{*}{ Local (2) } & medição/colheita & 1 & $2230334422 * *$ & $690,3195 *$ \\
\hline & Clones & 93 & $15920933^{* *}$ & $575,6220 * *$ \\
\hline & resíduo & 93 & 9287081 & 169,3416 \\
\hline & $\overline{\mathrm{CV}}(\%)$ & & 58,31 & 18,47 \\
\hline & Vfp: & & 3364600,4819 & 201,4480 \\
\hline & Vet: & & 9309806,6858 & 170,5693 \\
\hline & Vf: & & 12674407,17 & 372,0173 \\
\hline & $r=h 2:$ & & $0,27+/-0,107^{1}$ & $0,54+/-0,152^{1}$ \\
\hline & $\mathrm{rm}:$ & & 0,4195 & 0,7025 \\
\hline & Acm: & & 0,6477 & 0,8382 \\
\hline & Eficiência & & 1,26 & 1,14 \\
\hline & Média geral & & 5220,1469 & 70,3941 \\
\hline \multirow{12}{*}{ Local (3) } & medição/colheita & 1 & 10136714055 ** & $301,9313 *$ \\
\hline & Clones & 171 & $25443379 * *$ & $399,7913 * *$ \\
\hline & resíduo & 171 & 16250851 & 59,7232 \\
\hline & $\mathrm{CV}(\%)$ & & 35,05 & 10,97 \\
\hline & Vfp: & & 4602566,5938 & 169,5680 \\
\hline & Vet: & & 16290284,0083 & 59,9183 \\
\hline & Vf: & & 20892850,6021 & 229,4864 \\
\hline & $\mathrm{r}=\mathrm{h} 2:$ & & $0,22+/-0,071^{1}$ & $0,74+/-0,131^{1}$ \\
\hline & rm: & & 0,3610 & 0,8498 \\
\hline & Acm: & & 0,6008 & 0,9218 \\
\hline & Eficiência & & 1,28 & 1,07 \\
\hline & Média geral & & 11492,7548 & 70,3751 \\
\hline
\end{tabular}

${ }^{1}$ Desvio-padrão da estimativa.*, ** diferença significativa a $1 \%$ e $5 \%$, respectivamente, pelo teste de F.

Vfp.:variância fenotípica permanente entre plantas (genotípica + ambiental permanente de uma colheita para outra).

Vet.: variância de ambiente temporário; Vf.: variância fenotípica individual; $\mathrm{r}=\mathrm{h} 2 .:$ repetibilidade individual; rm.: repetibilidade da média de $m$ colheitas ou $m$ medidas repetidas $\mathrm{m}=2$; Acm.: acurácia da seleção baseada na média de $m$ colheitas ou medidas repetidas; Eficiência.: eficiência na seleção. 
TABELA 3 - Valores fenotípicos permanentes e ganhos genéticos com a seleção dos 30 melhores clones de pessegueiro classificados dentre todos os avaliados no local 1, para os caracteres produção (gramas) de frutos/planta e massa média dos frutos, visando à propagação assexuada.

\begin{tabular}{|c|c|c|c|c|c|c|c|c|c|c|}
\hline \multirow[b]{3}{*}{ Ordem } & \multicolumn{10}{|c|}{ LOCAL (1) } \\
\hline & \multicolumn{5}{|c|}{ PTF } & \multicolumn{5}{|c|}{ MMF } \\
\hline & Clone & $f p$ & $u+f p$ & Ganho & $\begin{array}{l}\text { Nova } \\
\text { Média }\end{array}$ & Clone & $f p$ & $u+f p$ & Ganho & $\begin{array}{l}\text { Nova } \\
\text { Média }\end{array}$ \\
\hline 1 & 0316 & 7049,01 & 13625,32 & 7049,01 & 13625,32 & 0328 & 41,33 & 102,45 & 41,33 & 102,45 \\
\hline 2 & 0226 & 5716,71 & 12293,02 & 6382,86 & 12959,17 & 0740 & 40,46 & 101,59 & 40,89 & 102,02 \\
\hline 3 & 0230 & 4442,16 & 11018,47 & 5735,96 & 12312,27 & 1307 & 40,04 & 101,16 & 40,61 & 101,73 \\
\hline 4 & 0931 & 4396,23 & 10972,54 & 5401,03 & 11977,34 & 0926 & 32,70 & 93,83 & 38,63 & 99,76 \\
\hline 5 & 0736 & 4211,14 & 10787,45 & 5163,05 & 11739,36 & 1042 & 31,47 & 92,59 & 37,20 & 98,32 \\
\hline 6 & 0107 & 4113,09 & 10689,41 & 4988,06 & 11564,37 & 0240 & 29,82 & 90,95 & 35,97 & 97,10 \\
\hline 7 & 0111 & 4066,05 & 10642,36 & 4856,34 & 11432,65 & 0841 & 29,31 & 90,43 & 35,02 & 96,14 \\
\hline 8 & 0631 & 4011,11 & 10587,42 & 4750,69 & 11327,00 & 0732 & 28,04 & 89,17 & 34,14 & 95,27 \\
\hline 9 & 0426 & 4001,25 & 10577,56 & 4667,42 & 11243,73 & 1941 & 26,65 & 87,78 & 33,31 & 94,44 \\
\hline 10 & 0470 & 3925,18 & 10501,49 & 4593,19 & 11169,50 & 1043 & 25,64 & 86,76 & 32,54 & 93,67 \\
\hline 11 & 0526 & 3460,32 & 10036,64 & 4490,20 & 11066,51 & 1239 & 25,31 & 86,44 & 31,89 & 93,01 \\
\hline 12 & 0113 & 3388,48 & 9964,79 & 4398,39 & 10974,70 & 0617 & 24,81 & 85,93 & 31,30 & 92,42 \\
\hline 13 & 2728 & 3308,19 & 9884,50 & 4314,53 & 10890,84 & 1841 & 23,11 & 84,23 & 30,67 & 91,79 \\
\hline 14 & 2828 & 3143,66 & 9719,97 & 4230,90 & 10807,21 & 0141 & 20,47 & 81,59 & 29,94 & 91,07 \\
\hline 15 & 1928 & 3089,85 & 9666,16 & 4154,83 & 10731,14 & 0115 & 20,05 & 81,17 & 29,28 & 90,41 \\
\hline 16 & 0228 & 3079,99 & 9656,30 & 4087,65 & 10663,96 & 0232 & 18,80 & 79,93 & 28,62 & 89,75 \\
\hline 17 & 0844 & 3075,76 & 9652,07 & 4028,13 & 10604,44 & 0344 & 18,76 & 79,89 & 28,04 & 89,17 \\
\hline 18 & 0131 & 3002,51 & 9578,82 & 3971,15 & 10547,46 & 1407 & 17,08 & 78,21 & 27,43 & 88,56 \\
\hline 19 & 0204 & 2954,62 & 9530,93 & 3917,65 & 10493,96 & 2541 & 16,65 & 77,77 & 26,87 & 87,99 \\
\hline 20 & 0336 & 2940,53 & 9516,84 & 3868,79 & 10445,10 & 1741 & 16,18 & 77,30 & 26,33 & 87,46 \\
\hline 21 & 3228 & 2929,26 & 9505,57 & 3824,05 & 10400,36 & 0112 & 16,05 & 77,18 & 25,84 & 86,97 \\
\hline 22 & 1770 & 2623,58 & 9199,89 & 3769,49 & 10345,80 & 0470 & 13,55 & 74,68 & 25,28 & 86,41 \\
\hline 23 & 1307 & 2572,87 & 9149,18 & 3717,46 & 10293,77 & 0217 & 13,25 & 74,38 & 24,76 & 85,89 \\
\hline 24 & 1136 & 2529,20 & 9105,51 & 3667,95 & 10244,26 & 0241 & 12,86 & 73,98 & 24,26 & 85,39 \\
\hline 25 & 0126 & 2484,13 & 9060,44 & 3620,60 & 10196,91 & 0117 & 12,48 & 73,61 & 23,79 & 84,92 \\
\hline 26 & 0337 & 2395,66 & 8971,97 & 3573,48 & 10149,79 & 0439 & 11,72 & 72,85 & 23,33 & 84,46 \\
\hline 27 & 0836 & 2367,21 & 8943,52 & 3528,81 & 10105,12 & 0104 & 11,61 & 72,74 & 22,90 & 84,02 \\
\hline 28 & 1828 & 2247,76 & 8824,07 & 3483,05 & 10059,36 & 0970 & 11,39 & 72,52 & 22,48 & 83,61 \\
\hline 29 & 0130 & 2170,56 & 8746,87 & 3437,80 & 10014,11 & 0338 & 11,28 & 72,41 & 22,10 & 83,23 \\
\hline 30 & 0626 & 2151,69 & 8728,00 & 3394,93 & 9971,24 & 2341 & 11,26 & 72,38 & 21,74 & 82,86 \\
\hline
\end{tabular}

fp.: efeito fenotípico permanente;

$\mathrm{u}+\mathrm{fp}$. : valor fenotípico permanente.

Ganho: ganho genético na variável objeto da seleção. Ganho? (Descrever).

Nova média: nova média do material genético após a seleção. Nova média (idem). Fazer o mesmo para as outras Tabelas. 
TABELA 4 - Valores fenotípicos permanentes e ganhos genéticos com a seleção dos 30 melhores clones de pessegueiro classificados dentre todos os avaliados no local 2, para os caracteres produção (gramas) de frutos/planta e massa média dos frutos, visando à propagação assexuada.

\begin{tabular}{|c|c|c|c|c|c|c|c|c|c|c|}
\hline \multirow[b]{3}{*}{ Ordem } & \multicolumn{9}{|c|}{ LOCAL (2) } & \\
\hline & \multicolumn{5}{|c|}{ PTF } & \multicolumn{5}{|c|}{ MMF } \\
\hline & Clone & $f p$ & $u+f p$ & Ganho & $\begin{array}{l}\text { Nova } \\
\text { Média }\end{array}$ & Clone & $f p$ & $u+f p$ & Ganho & $\begin{array}{l}\text { Nova } \\
\text { Média }\end{array}$ \\
\hline 1 & 0126 & 3980,33 & 9200,48 & 3980,33 & 9200,48 & 1239 & 58,19 & 128,58 & 58,19 & 128,58 \\
\hline 2 & 0607 & 3416,26 & 8636,40 & 3698,29 & 8918,44 & 0439 & 40,70 & 111,09 & 49,44 & 119,84 \\
\hline 3 & 1843 & 2967,14 & 8187,29 & 3454,57 & 8674,72 & 0939 & 27,91 & 98,30 & 42,27 & 112,66 \\
\hline 4 & 2741 & 2514,03 & 7734,18 & 3219,44 & 8439,59 & 2541 & 23,94 & 94,34 & 37,68 & 108,08 \\
\hline 5 & 1444 & 2207,77 & 7427,92 & 3017,11 & 8237,25 & 0244 & 23,18 & 93,58 & 34,78 & 105,18 \\
\hline 6 & 1507 & 2156,38 & 7376,52 & 2873,65 & 8093,80 & 0839 & 19,57 & 89,96 & 32,25 & 102,64 \\
\hline 7 & 0204 & 1900,46 & 7120,60 & 2734,62 & 7954,77 & 1444 & 16,63 & 87,02 & 30,02 & 100,41 \\
\hline 8 & 1443 & 1694,88 & 6915,03 & 2604,66 & 7824,80 & 1170 & 13,69 & 84,09 & 27,98 & 98,37 \\
\hline 9 & 2443 & 1641,39 & 6861,54 & 2497,63 & 7717,77 & 1941 & 13,51 & 83,90 & 26,37 & 96,76 \\
\hline 10 & 0643 & 1499,80 & 6719,94 & 2397,84 & 7617,99 & 0141 & 12,30 & 82,69 & 24,96 & 95,36 \\
\hline 11 & 1770 & 1435,82 & 6655,96 & 2310,39 & 7530,53 & 1741 & 11,74 & 82,13 & 23,76 & 94,15 \\
\hline 12 & 1070 & 1394,91 & 6615,06 & 2234,10 & 7454,24 & 2141 & 10,61 & 81,01 & 22,66 & 93,06 \\
\hline 13 & 0426 & 1347,71 & 6567,86 & 2165,91 & 7386,06 & 0142 & 10,12 & 80,52 & 21,70 & 92,09 \\
\hline 14 & 0307 & 1313,10 & 6533,25 & 2105,00 & 7325,14 & 0970 & 9,60 & 80,00 & 20,84 & 91,23 \\
\hline 15 & 0843 & 1308,70 & 6528,84 & 2051,91 & 7272,06 & 0237 & 8,26 & 78,66 & 20,00 & 90,39 \\
\hline 16 & 2441 & 1247,02 & 6467,17 & 2001,61 & 7221,75 & 0144 & 7,86 & 78,25 & 19,24 & 89,63 \\
\hline 17 & 2643 & 1171,51 & 6391,65 & 1952,78 & 7172,92 & 0507 & 7,46 & 77,85 & & 88,94 \\
\hline 18 & 1607 & 1068,72 & 6288,86 & 1903,66 & 7123,81 & 1042 & 5,86 & 76,25 & 17,23 & 87,63 \\
\hline 19 & 1241 & 992,15 & 6212,30 & 1855,69 & 7075,83 & 3641 & 4,67 & 75,06 & 16,60 & 87,00 \\
\hline 20 & 0642 & 914,54 & 6134,68 & 1808,63 & 7028,78 & 1007 & 4,57 & 74,96 & 16,03 & 86,42 \\
\hline 21 & 1139 & 885,17 & 6105,32 & 1764,66 & 6984,80 & 1139 & 4,42 & 74,81 & 15,50 & 85,90 \\
\hline 22 & 2043 & 824,34 & 6044,48 & 1721,91 & 6942,06 & 1770 & 4,29 & 74,68 & 15,02 & 85,41 \\
\hline 23 & 1107 & 804,41 & 6024,55 & 1682,02 & 6902,17 & 2743 & 4,25 & 74,65 & 14,57 & 84,96 \\
\hline 24 & 0443 & 765,60 & 5985,75 & 1643,84 & 6863,98 & 1743 & 3,57 & 73,96 & 14,13 & 84,52 \\
\hline 25 & 0670 & 567,37 & 5787,51 & 1600,78 & 6820,93 & 0641 & 3,56 & 73,96 & 13,72 & 84,11 \\
\hline 26 & 0140 & 546,39 & 5766,54 & 1560,23 & 6780,37 & 2343 & 3,37 & 73,76 & 13,34 & 83,73 \\
\hline 27 & 0207 & 481,36 & 5701,51 & 1520,27 & 6740,41 & 4043 & 3,07 & 73,47 & 12,97 & 83,36 \\
\hline 28 & 1243 & 476,12 & 5696,26 & 1482,98 & 6703,12 & 0104 & 3,00 & 73,39 & 12,63 & 83,02 \\
\hline 29 & 0842 & 390,11 & 5610,26 & 1445,29 & 6665,44 & 3141 & 2,72 & 73,11 & 12,30 & 82,69 \\
\hline 30 & 0243 & 383,82 & 5603,96 & 1409,91 & 6630,06 & 0204 & 2,64 & 73,04 & 11,98 & 82,38 \\
\hline
\end{tabular}

fp.: efeito fenotípico permanente;

$\mathrm{u}+\mathrm{fp}$. : valor fenotípico permanente.

Ganho: ganho genético na variável objeto da seleção.

Nova média: nova média do material genético após a seleção. 
TABELA 5 - Valores fenotípicos permanentes e ganhos genéticos com a seleção dos 30 melhores clones de pessegueiro classificados dentre todos os avaliados no local 3, para os caracteres produção (gramas) de frutos/planta e massa média dos frutos, visando à propagação assexuada.

\begin{tabular}{|c|c|c|c|c|c|c|c|c|c|c|}
\hline \multirow[b]{3}{*}{ Ordem } & \multicolumn{10}{|c|}{ LOCAL (3) } \\
\hline & \multicolumn{5}{|c|}{ PTF } & \multicolumn{5}{|c|}{ MMF } \\
\hline & Clone & $f p$ & $u+f p$ & Ganho & $\begin{array}{c}\text { Nova } \\
\text { Média } \\
\end{array}$ & Clone & $f p$ & $u+f p$ & Ganho & $\begin{array}{c}\text { Nova } \\
\text { Média }\end{array}$ \\
\hline 1 & 0526 & 7306,40 & 18799,15 & 7306,40 & 18799,15 & 0740 & 45,62 & 116,00 & 45,62 & 116,00 \\
\hline 2 & 0443 & 3293,47 & 14786,22 & 5299,93 & 16792,69 & 1307 & 41,71 & 112,08 & 43,66 & 114,04 \\
\hline 3 & 0826 & 2743,97 & 14236,73 & 4447,95 & 15940,70 & 0339 & 33,34 & 103,71 & 40,22 & 110,60 \\
\hline 4 & 1107 & 2349,18 & 13841,93 & 3923,25 & 15416,01 & 0239 & 28,44 & 98,81 & 37,28 & 107,65 \\
\hline 5 & 1036 & 2225,70 & 13718,46 & 3583,74 & 15076,50 & 0240 & 28,31 & 98,69 & 35,48 & 105,86 \\
\hline 6 & 0137 & 2097,53 & 13590,29 & 3336,04 & 14828,80 & 2641 & 27,33 & 97,71 & 34,12 & 104,50 \\
\hline 7 & 0544 & 1878,20 & 13370,96 & 3127,78 & 14620,53 & 0141 & 27,24 & 97,62 & 33,14 & 103,52 \\
\hline 8 & 1443 & 1840,11 & 13332,87 & 2966,82 & 14459,58 & 1841 & 27,00 & 97,37 & 32,37 & 102,75 \\
\hline 9 & 0935 & 1824,95 & 13317,71 & 2839,95 & 14332,70 & 0941 & 26,35 & 96,73 & 31,70 & 102,08 \\
\hline 10 & 3441 & 1816,83 & 13309,58 & 2737,64 & 14230,39 & 2041 & 26,19 & 96,57 & 31,15 & 101,53 \\
\hline 11 & 1843 & 1782,71 & 13275,46 & 2650,82 & 14143,58 & 0507 & 25,42 & 95,79 & & 101,01 \\
\hline 12 & 0726 & 1693,17 & 13185,93 & 2571,02 & 14063,77 & 1239 & 23,03 & 93,41 & 30,00 & 100,37 \\
\hline 13 & 0740 & 1693,17 & 13185,93 & 2503,49 & 13996,25 & 1941 & 21,41 & 91,79 & 29,34 & 99,71 \\
\hline 14 & 0407 & 1647,14 & 13139,90 & 2442,32 & 13935,08 & 1741 & 19,23 & 89,60 & 28,62 & 98,99 \\
\hline 15 & 0204 & 1625,48 & 13118,23 & 2387,87 & 13880,62 & 0841 & 18,50 & 88,88 & 27,94 & 98,32 \\
\hline 16 & 1136 & 1592,98 & 13085,74 & 2338,19 & 13830,94 & 1043 & 18,41 & 88,79 & 27,35 & 97,72 \\
\hline 17 & 2643 & 1523,49 & 13016,24 & 2290,26 & 13783,02 & 0107 & 17,47 & 87,84 & 26,76 & 97,14 \\
\hline 18 & 0236 & 1436,84 & 12929,59 & 2242,85 & 13735,61 & 1441 & 17,37 & 87,75 & 26,24 & 96,62 \\
\hline 19 & 0426 & 1377,26 & 12870,02 & 2197,29 & 13690,05 & 0344 & 17,11 & 87,48 & 25,76 & 96,14 \\
\hline 20 & 0807 & 1362,82 & 12855,58 & 2155,57 & 13648,33 & 1407 & 16,30 & 86,67 & 25,29 & 95,66 \\
\hline 21 & 0143 & 1361,02 & 12853,77 & 2117,74 & 13610,49 & 2941 & 16,20 & 86,58 & 24,86 & 95,23 \\
\hline 22 & 0836 & 1345,67 & 12838,43 & 2082,64 & 13575,40 & 2541 & 15,55 & 85,92 & 24,43 & 94,81 \\
\hline 23 & 2441 & 1336,65 & 12829,40 & 2050,21 & 13542,96 & 0241 & 14,45 & 84,83 & 24,00 & 94,37 \\
\hline 24 & 0736 & 1314,99 & 12807,74 & 2019,57 & 13512,33 & 0744 & 13,81 & 84,19 & 23,57 & 93,95 \\
\hline 25 & 0404 & 1243,68 & 12736,44 & 1988,54 & 13481,29 & 0926 & 12,10 & 82,47 & 23,12 & 93,49 \\
\hline 26 & 0536 & 1167,86 & 12660,62 & 1956,97 & 13449,73 & 1244 & 11,21 & 81,58 & 22,66 & 93,03 \\
\hline 27 & 1336 & 1151,62 & 12644,37 & 1927,14 & 13419,90 & 0439 & 10,72 & 81,10 & 22,22 & 92,59 \\
\hline 28 & 0844 & 1142,59 & 12635,35 & 1899,12 & 13391,88 & 0238 & 10,36 & 80,73 & 21,79 & 92,17 \\
\hline 29 & 0926 & 1122,73 & 12615,49 & 1872,35 & 13365,11 & 0341 & 10,19 & 80,56 & 21,39 & 91,77 \\
\hline 30 & 2043 & 1094,75 & 12587,51 & 1846,43 & 13339,19 & 0440 & 9,08 & 79,45 & 20,98 & 91,36 \\
\hline
\end{tabular}

fp.: efeito fenotípico permanente;

$\mathrm{u}+\mathrm{fp}$. : valor fenotípico permanente.

Ganho: ganho genético na variável objeto da seleção.

Nova média: nova média do material genético após a seleção. 
TABELA 6 - Estimativas dos componentes da variância para os caracteres produção (gramas) de frutos/ planta (PTF) e massa média dos frutos (MMF) em clones de pessegueiro.

\begin{tabular}{|c|c|c|c|}
\hline \multicolumn{4}{|c|}{ Componentes de Variância (REML Individual) } \\
\hline & & PTF & MMF \\
\hline Vg & $=$ & 2713225,519 & 132,0248 \\
\hline Vperm & $=$ & 1597106,826 & 3,013761 \\
\hline Ve & $=$ & 8693720,129 & 101,7284 \\
\hline $\mathbf{V f}$ & $=$ & 13004052,47 & 236,7670 \\
\hline h2g & $=$ & $0,208645+-0,0576$ & $0,557615+-0,0942$ \\
\hline $\mathbf{r}$ & $=$ & $0,331461+-0,0726$ & $0,570344+-0,0952$ \\
\hline Acgen & $=$ & 0,6885 & 0,9091 \\
\hline c2perm & $=$ & 0,122816 & 0,012729 \\
\hline Média geral & $=$ & 7681,148088 & 65,496352 \\
\hline
\end{tabular}

Vg.: variância genotípica; Vperm.:.variância de ambiente permanente; Vf.: variância fenotípica individual. h2g.: herdabilidade de parcelas individuais no sentido amplo, ou seja, efeitos genotípicos totais; r.: repetibilidade a nível de parcelas, dada por (Vg + Vperm)/Vf; Acgen: acurácia na seleção dos genótipos; $c 2 p e r m=c 2$. : coeficiente de determinação dos efeitos de ambiente permanente.

TABELA 7 - Valores genotípicos e ganhos genéticos com a seleção dos 30 melhores clones de pessegueiro classificados dentre os coincidentes nos três locais de avaliação, para os caracteres produção (gramas) de frutos/planta e massa média dos frutos, visando à propagação assexuada.

\begin{tabular}{|c|c|c|c|c|c|c|c|c|c|c|}
\hline \multirow[b]{2}{*}{ Ordem } & \multicolumn{5}{|c|}{ PTF } & \multicolumn{5}{|c|}{ MMF } \\
\hline & Clone & $g$ & $u+g$ & Ganho & $\begin{array}{l}\text { Nova } \\
\text { Média }\end{array}$ & Clone & $g$ & $u+g$ & Ganho & $\begin{array}{l}\text { Nova } \\
\text { Média }\end{array}$ \\
\hline 1 & 0126 & 2993,74 & 10674,89 & 2993,74 & 10674,89 & 1239 & 43,60 & 109,10 & 43,60 & 109,10 \\
\hline 2 & 0204 & 2797,62 & 10478,77 & 2895,68 & 10576,83 & 0439 & 26,81 & 92,30 & 35,21 & 100,70 \\
\hline 3 & 0426 & 2769,20 & 10450,35 & 2853,52 & 10534,67 & 1941 & 24,90 & 90,40 & 31,77 & 97,27 \\
\hline 4 & 1843 & 2302,98 & 9984,13 & 2715,89 & 10397,03 & 0141 & 24,02 & 89,52 & 29,83 & 95,33 \\
\hline 5 & 0607 & 2299,13 & 9980,28 & 2632,54 & 10313,68 & 2541 & 23,38 & 88,87 & 28,54 & 94,04 \\
\hline 6 & 0443 & 2271,20 & 9952,34 & 2572,31 & 10253,46 & 1741 & 19,37 & 84,86 & 27,01 & 92,51 \\
\hline 7 & 1507 & 1925,38 & 9606,53 & 2479,89 & 10161,04 & 1042 & 18,67 & 84,17 & 25,82 & 91,32 \\
\hline 8 & 1770 & 1889,74 & 9570,89 & 2406,13 & 10087,27 & 0244 & 16,21 & 81,70 & 24,62 & 90,12 \\
\hline 9 & 1443 & 1661,83 & 9342,98 & 2323,43 & 10004,57 & 0839 & 13,69 & 79,18 & 23,40 & 88,90 \\
\hline 10 & 0844 & 1532,37 & 9213,52 & 2244,32 & 9925,47 & 0104 & 12,46 & 77,96 & 22,31 & 87,81 \\
\hline 11 & 1107 & 1505,40 & 9186,55 & 2177,15 & 9858,29 & 0970 & 9,59 & 75,09 & 21,15 & 86,65 \\
\hline 12 & 1070 & 1374,88 & 9056,03 & 2110,29 & 9791,44 & 2141 & 9,12 & 74,61 & 20,15 & 85,65 \\
\hline 13 & 2741 & 1269,88 & 8951,03 & 2045,64 & 9726,79 & 0142 & 7,70 & 73,20 & 19,19 & 84,69 \\
\hline 14 & 2441 & 1226,54 & 8907,68 & 1987,14 & 9668,28 & 1444 & 7,22 & 72,72 & 18,34 & 83,84 \\
\hline 15 & 0544 & 1208,72 & 8889,86 & 1935,24 & 9616,39 & 0539 & 6,64 & 72,13 & 17,56 & 83,05 \\
\hline 16 & 0137 & 1151,40 & 8832,55 & 1886,25 & 9567,40 & 3541 & 5,98 & 71,48 & 16,84 & 82,33 \\
\hline 17 & 2843 & 1120,58 & 8801,72 & 1841,21 & 9522,36 & 1007 & 5,90 & 71,39 & 16,19 & 81,69 \\
\hline 18 & 0337 & 1030,41 & 8711,56 & 1796,17 & 9477,32 & 1770 & 5,21 & 70,70 & 15,58 & 81,08 \\
\hline 19 & 2841 & 947,67 & 8628,82 & 1751,51 & 9432,66 & 1443 & 4,94 & 70,43 & 15,02 & 80,52 \\
\hline 20 & 0404 & 928,41 & 8609,55 & 1710,35 & 9391,50 & 0237 & 4,13 & 69,63 & 14,48 & 79,97 \\
\hline 21 & 2043 & 829,67 & 8510,82 & 1668,42 & 9349,57 & 2343 & 3,84 & 69,33 & 13,97 & 79,47 \\
\hline 22 & 0307 & 825,82 & 8506,97 & 1630,12 & 9311,27 & 0741 & 3,30 & 68,80 & 13,49 & 78,98 \\
\hline 23 & 1444 & 783,92 & 8465,06 & 1593,33 & 9274,47 & 0642 & 2,99 & 68,49 & 13,03 & 78,53 \\
\hline 24 & 2643 & 750,68 & 8431,83 & 1558,22 & 9239,36 & 0670 & 2,84 & 68,34 & 12,60 & 78,10 \\
\hline 25 & 0807 & 644,72 & 8325,87 & 1521,68 & 9202,82 & 0204 & 2,67 & 68,16 & 12,21 & 77,70 \\
\hline 26 & 0670 & 609,56 & 8290,71 & 1486,59 & 9167,74 & 1041 & 2,61 & 68,11 & 11,84 & 77,33 \\
\hline 27 & 1243 & 558,03 & 8239,18 & 1452,20 & 9133,35 & 2043 & 2,56 & 68,06 & 11,49 & 76,99 \\
\hline 28 & 3243 & 522,10 & 8203,25 & 1418,99 & 9100,13 & 0137 & 2,51 & 68,01 & 11,17 & 76,67 \\
\hline 29 & 0407 & 468,93 & 8150,08 & 1386,22 & 9067,37 & 1743 & 2,14 & 67,64 & 10,86 & 76,36 \\
\hline 30 & 0643 & 434,73 & 8115,88 & 1354,51 & 9035,66 & 1139 & 2,06 & 67,56 & 10,57 & 76,06 \\
\hline
\end{tabular}

g.: efeito genotípico predito;

$\mathrm{u}+\mathrm{g} .:$ média genotípica ou valores genotípicos.

Ganho: ganho genético na variável objeto da seleção.

Nova média: nova média do material genético após a seleção. 


\section{CONCLUSÃO}

Todos os caracteres apresentam considerável variabilidade genética, com estimativas de coeficientes de repetibilidade $(r)$ consideradas de média a alta magnitude $(0,54$ a 0,74$)$ para o caráter MMF e de baixa a média magnitude $(0,22$ a 0,39$)$ para o caráter PTF; 2 - Os clones 1770 e 1443 apresentam bom desempenho na média de todos os locais, enquanto os clones 0470 e 1307 se destacam no local 1, o clone 1444 no local 2, os clones, 0740 e 0926 no local 3 e o clone 1770 nos locais 1 e 2 de avaliação.

\section{REFERÊNCIAS}

BARBOSA, W.; OJIMA, M.; DALL'ORTO, F.A.C.; MARTINS, F.P.; CASTRO, J.L. de; SANTOS, R.R. dos. Avaliação de pessegueiros e nectarineiras introduzidos no Brasil, procedentes da Flórida-EUA. Scientia agricola, Piracicaba, v. 54, n.3, p. 152-159, 1997.

CEAGESP. A Saúde do pêssego no mercado. São Paulo, 2005. Disponível em: http://www.ceagesp.gov.br/produtor/estudos/anexos/pessego.pdf/ view? searchterm=pessego $>$. Acesso em: 24 jan. 2011.

CORNACCHIA, G.; CRUZ, C.D.; LOBO, P.R.; PIRES, I.E. Estimativas do coeficiente de repetibilidade para características fenotípicas de procedências de Pinus tecunumanii (Schw.) Eguiluz, Perry e Pinus caribaea var. hondurensis Barret, Golfari. Revista Árvore, Viçosa, MG, v.19, n.3, p.333-345, 1995.

COSTA, J.G. da. Estimativas de repetibilidade de alguns caracteres de produção em mangueira. Ciência Rural, Santa Maria, v.33, n.2, p.263-266, 2003.
LOPES, R.; BRUCKNER, C.H.; CRUZ, C.D.; LOPES, M.T.G.; FREITAS, G.B. de. Repetibilidade de características do fruto de aceroleira. Pesquisa Agropecuária Brasileira, Brasília, v.36, n.3, p.507513, 2001.

FALCONER, D.S. Introdução à genética quantitativa. Viçosa: UFV, 1987. 279p.

MEDEIROS, C. A. B.; RASEIRA, M. C. B. A cultura do Pessegueiro. Brasília: Embrapa-SPI; Pelotas: Embrapa-CPACT, 1998. 350p.

NEGREIROS, J.R.S.; SARAIVA, L.L.; OLIVEIRA, T.K.; ÁlVARES, V.S.; RONCATTO, G. Estimativas de repetibilidade de caracteres de produção em laranjeiras-doces no Acre. Pesquisa Agropecuária Brasileira, Brasília, v.43, n.12, p.1763-1768, 2008.

RESENDE, M.D.V. de. Genética biométrica e estatística no melhoramento de plantas perenes. Brasília: Embrapa Informação Tecnológica, 2002. $975 \mathrm{p}$.

RESENDE, M.D.V. de. Software SELEGENREML/BLUP: sistema estatístico e seleção genética computadorizada via modelos lineares mistos. Colombo: Embrapa Florestas, 2007. 359p.

SANTOS, C.A.F. In situ evaluation of fruit yield and estimation of repeatability coeffi cient for major fruit traits of umbu tree [Spondias tuberosa (Anacardiaceae)] in the semi-arid region of Brazil. Genetic Resources and Crop Evolution, Dordrecht, v.46, n. 5, p.455-460, 1999.

STURION, J.A.; RESENDE, M.D.V. Seleção de progênies de erva-mate (Ilex paraguarensis St. Hil.) para produtividade, estabilidade e adaptabilidade temporal de massa foliar. Boletim de Pesquisa Florestal, Colombo, n.50, p.37-51, 2005. 